\title{
Surface renewal as a significant mechanism for dust emission
}

\author{
Jie Zhang ${ }^{1,2}$, Zhenjiao Teng ${ }^{2}$, Ning Huang ${ }^{1,2}$, Lei Guo ${ }^{2}$, and Yaping Shao ${ }^{3}$ \\ ${ }^{1}$ Key Laboratory of Mechanics on Disaster and Environment in Western China (Lanzhou University), Ministry of Education, \\ Lanzhou 730000, China \\ ${ }^{2}$ School of Civil Engineering and Mechanics, Lanzhou University, Lanzhou 730000, China \\ ${ }^{3}$ Institute for Geophysics and Meteorology, University of Cologne, 50937 Cologne, Germany
}

Correspondence to: Ning Huang (huangn@1zu.edu.cn)

Received: 18 May 2016 - Published in Atmos. Chem. Phys. Discuss.: 13 July 2016

Revised: 22 November 2016 - Accepted: 28 November 2016 - Published: 15 December 2016

\begin{abstract}
Wind tunnel experiments of dust emissions from different soil surfaces are carried out to better understand dust emission mechanisms. The effects of surface renewal on aerodynamic entrainment and saltation bombardment are analyzed in detail. It is found that flow conditions, surface particle motions (saltation and creep), soil dust content and ground obstacles all strongly affect dust emission, causing its rate to vary over orders of magnitude. Aerodynamic entrainment is highly effective, if dust supply is unlimited, as in the first $2-3$ min of our wind tunnel runs. While aerodynamic entrainment is suppressed by dust supply limits, surface renewal through the motion of surface particles appears to be an effective pathway to remove the supply limit. Surface renewal is also found to be important to the efficiency of saltation bombardment. We demonstrate that surface renewal is a significant mechanism affecting dust emission and recommend that this mechanism be included in future dust models.
\end{abstract}

\section{Introduction}

Three dust emission mechanisms have been identified, including (1) aerodynamic entrainment, (2) saltation bombardment and (3) aggregates disintegration (Shao, 2008; Kok et al., 2012; Újvári et al., 2016). In spite of much research effort, many questions remain unanswered in relation to the process of dust emission. For example, in most existing dust emission schemes, aerodynamic entrainment is assumed to be small and negligible. It is however questionable, to what extent and under what conditions this assumption is justified because there are hardly any data that enable a rigorous com- parison of aerodynamic entrainment from natural soil surfaces with the other dust emission mechanisms. For natural soils, dust emission is usually "supply limited" (Shao, 2008; Macpherson et al., 2008; Újvári et al., 2016); i.e., the emission is limited by the availability of free particles on the soil surface, rather than by the shear stress that wind exerts (note that "supply limited" in this paper only refers to a lack of supply of fine soil particles, but not saltators). However, "supply limit" is not a quantified term in published emission models, as little is known about its spatial and temporal variations. The argument for the neglect of aerodynamic entrainment is that dust particles have relatively large cohesive forces and are resistant to aerodynamic lift; thus, saltation bombardment and aggregates disintegration are the dominant mechanisms for dust emission (Greeley and Iversen, 1985; Shao et al., 1993). Researchers have noted there are obvious differences in dust emission from disturbed and undisturbed soils (Macpherson et al., 2008; MP2008 hereafter). This is because soil disturbance replenishes dust supply to aerodynamic entrainment and modifies the aerodynamic properties of the surface, which may enhance momentum transfer from the atmosphere to the surface. Further, in existing dust models, the conditions of the surface subject to erosion are assumed to be stationary. In reality, during an erosion event, surface self-disturbance occurs due to top soil removal and particle impact; i.e., a surface renewal process takes place, which in general enhances the supply of dust for aerodynamic entrainment. We argue that under the conditions of strong surface renewal, aerodynamic entrainment may be a significant mechanism for dust emission.

In this work, we simulate three typical landforms in a wind tunnel experiment, namely, a farmland surface, a desert sur- 
face and a loess surface (see Sect. 3 for details). We then seek to quantify the contributions of three dust emission mechanisms to the total dust flux for the different landforms. Using the wind tunnel observations, we demonstrated that supply limit of free dust is a major factor that suppresses aerodynamic entrainment, but surface renewal through saltation and creep provides an important pathway to enhance the free dust supply for aerodynamic entrainment. Thus, for surfaces with strong renewal and sufficient free dust supply, aerodynamic entrainment becomes a non-negligible process for dust emission.

\section{Background of dust emission mechanisms}

In general, dust emission flux, $F$, is considered to be caused by three mechanisms and can be expressed as

$F=F_{\mathrm{a}}+F_{\mathrm{b}}+F_{\mathrm{c}}$,

where $F_{\mathrm{a}}, F_{\mathrm{b}}$ and $F_{\mathrm{c}}$ are respectively the fluxes arising from aerodynamic entrainment, saltation bombardment and aggregates disintegration. $F_{\mathrm{a}}$ is directly related to surface shear stress, while $F_{\mathrm{b}}$ and $F_{\mathrm{c}}$ depend on saltation. Here we will briefly review the studies on dust emission mechanisms and summarize the dust emission flux formulations. We will then introduce the basic assumptions of our study.

\subsection{Aerodynamic entrainment}

Aerodynamic entrainment refers to direct dust uplift from the surface into the atmosphere by aerodynamic forces. It has been suggested that the dust flux arising from aerodynamic entrainment is insignificant because aerodynamic lift force for small particles is in general small compared to interparticle adhesion. Based on their wind tunnel experiments, Loosmore and Hunt (2000; LS2000 hereafter) suggested that

$F_{\mathrm{a}}=3.6 u_{*}^{3}$,

where $F_{\mathrm{a}}$ is in $\mu \mathrm{g} \mathrm{m}^{-2} \mathrm{~s}^{-1}$. Shao (2008) suggested that interparticle cohesive force is a stochastic variable, such that there always exists in nature a proportion of dust that is free, i.e., dust for which inter-particle cohesion is weak. Several studies have demonstrated that $F_{\mathrm{a}}$ is not always negligible (Kjelgaard et al., 2004; MP2008; Klose and Shao, 2012; Sweeney and Mason, 2013), but the key factors that determine aerodynamic entrainment remain poorly understood. Moreover, Loosmore and Hunt (2000) conducted the wind tunnel experiments by using "Arizona Test Dust" (ISO-12103-1) to produce very smooth test beds. The investigation of dust emission caused by aerodynamic entrainment over natural and rough surfaces is still lacking.

\subsection{Saltation bombardment}

Saltation bombardment is considered as the central mechanism of dust emission and has been extensively studied.
Based on field experiments (Gillette, 1974, 1977, 1981), Gillette and Passi (1988; GP88 hereafter) proposed an empirical formula for dust flux due to saltation bombardment, $F_{\mathrm{b}}$, as a function of friction velocity

$F_{\mathrm{b}}=c \cdot u_{*}^{n}\left(1-\frac{u_{*_{t}}}{u_{*}}\right)$,

where $c$ is an empirical constant and $n$ is suggested to be 4 (GP88). According to existing field measurements, Shao (2008) stated that dust emission flux can be proportional to $u_{*}^{n}$ but with $n$ varying between 2.9 and 4.4 , depending on soil type and soil surface conditions. Many other studies have been carried out on sandblasting dust emission. For example, Marticorena and Bergametti (1995) suggested that dust emission flux is dependent on streamwise saltation flux and soil clay content, and Alfaro and Gomes (2001) suggested that sandblasting results in dust emission from three separate lognormal particle size modes, and the contribution of the modes depends on the particle binding energy and the kinetic energy of impacting saltators.

Based on the wind tunnel observations by Rice et al. (1996a, b) and Shao et al. (1993, 1996), Lu and Shao (1999; LS99 hereafter) and Shao (2000, 2001) argued that a blasting saltator, upon its impact, causes a bombardment effect that results in dust emission. The latter authors derived a physical expression for dust emission by saltation:

$F_{\mathrm{b}}=\frac{c_{\mathrm{b}} g \xi \rho_{\mathrm{b}}}{P}\left(1+14 u_{*} \sqrt{\frac{\rho_{\mathrm{b}}}{P}}\right) Q$,

where $c_{\mathrm{b}}$ is a constant; $g$ is gravitational acceleration; $\xi$ is the mass fraction of dust inside the crater; $\rho_{\mathrm{b}}$ is the soil bulk density; $P$ is the horizontal component of soil plastic pressure determined by soil property; and $Q$ represents saltation intensity, which can be estimated by using the Owen model as shown in the next section.

\subsection{Aggregates disintegration}

Studies on aggregates disintegration are rare. Shao (2001) presented a dust emission model that accounts for both the effect of saltation bombardment and aggregates disintegration. This model, as simplified in Shao (2004; S04 hereafter), can be summarized as follows:

$$
\begin{aligned}
& F_{\mathrm{b}}+F_{\mathrm{c}}=\sum_{i=1}^{I} F\left(d_{i}\right), \\
& F\left(d_{i}\right)=\int_{d_{1}}^{d_{2}} F\left(d_{i}, d_{\mathrm{s}}\right) p\left(d_{\mathrm{s}}\right) \delta d_{\mathrm{s}},
\end{aligned}
$$




$$
\begin{aligned}
F\left(d_{i} d_{\mathrm{s}}\right)=c_{y} \xi_{\mathrm{f}_{i}}\left[(1-\gamma)+\gamma \sigma_{\mathrm{p}}\right]\left(1+\sigma_{\mathrm{m}}\right) \frac{g Q\left(d_{\mathrm{s}}\right)}{u_{*}^{2}} \\
Q\left(d_{\mathrm{s}}\right)=c_{0} \frac{\rho}{g} u_{*}^{3}\left(1-\frac{u_{*_{t}}^{2}\left(d_{\mathrm{s}}\right)}{u_{*}^{2}}\right) \\
\quad \text { with } c_{0}=0.25+\frac{v_{\mathrm{t}}}{3 u_{*}}(\text { Owen, 1964), }
\end{aligned}
$$

where $d_{i}$ is the particle size of the $i$ th bin out of the total $I$ bins; $d_{\mathrm{s}}$ is the particle size of the saltator; $F\left(d_{i}\right)$ represents the flux of dust of size $d_{i}$; and $F\left(d_{i} d_{\mathrm{s}}\right)$ represents the fraction of $F\left(d_{i}\right)$, which is caused by saltators of size $d_{\mathrm{s}} . d_{1}$ and $d_{2}$ are the lower and upper limits of $d_{\mathrm{s}}$. $p\left(d_{\mathrm{s}}\right)=\gamma p_{\mathrm{m}}\left(d_{\mathrm{s}}\right)+(1-\gamma) p_{\mathrm{f}}\left(d_{\mathrm{s}}\right)$ is the particle size distribution of $d_{\mathrm{s}}, p_{\mathrm{m}}\left(d_{\mathrm{s}}\right)$ and $p_{\mathrm{f}}\left(d_{\mathrm{s}}\right)$ are respectively the distributions of saltators with statuses of minimally and fully disturbances, $\gamma=\exp \left[-\left(u_{*}-u_{*_{t}}\right)^{3}\right]$ (Shao et al., 2011), $c_{y}$ is a dimensionless coefficient, $\xi_{\mathrm{f}_{i}}$ is total dust fraction of the $i$ th bin, $\sigma_{\mathrm{p}}$ is the ratio of aggregated dust to free dust and $\sigma_{\mathrm{m}}$ is the mass ratio of ejectiles to saltators (i.e., bombardment efficiency) derived from the saltation model by Lu and Shao (1999). Saltation intensity $Q\left(d_{\mathrm{s}}\right)$ is evaluated by Owen model (Eq. 8; where $\rho$ is air density, $1.25 \mathrm{~kg} \mathrm{~m}^{-3}$ ) and the particle terminal velocity is calculated by $v_{\mathrm{t}}=1.66\left(\sigma_{\varphi} g d_{\mathrm{s}}\right)^{1 / 2}$ (Shao, 2008), with particleto-air density ratios $\sigma_{\varphi}=2120$. Equation (5) sums the dust fluxes of all size bins and Eq. (6) gives the dust flux of particles in the $i$ th bin. In the end, emission dust flux is found to be proportional to $Q\left(d_{\mathrm{s}}\right)$, but the proportionality depends on soil texture and soil plastic pressure. Further simplification indicates that at high soil plastic pressure $\left(>3 \times 10^{5} \mathrm{~Pa}\right), \sigma_{\mathrm{m}}$ becomes negligibly small $(<0.1)$ under normal wind conditions, and saltation bombardment diminishes to such an extent that aggregates disintegration prevails.

Kok et al. (2014) proposed a dust emission parameterization by using a combination of theory and numerical simulations. Their model primarily considers dust emission by aggregates disintegration and is in good agreement with a quality-controlled compilation of experimental measurements. But it is difficult to distinguish the contributions of the different dust emission mechanisms from experimental data (especially for field measurement). Furthermore, it appears to be untenable to assume that dust emission is mainly caused by sandblasted fragmentation. We argue that aerodynamic entrainment should not be simply ignored and a series of wind tunnel experiments are designed to verify our argument.

Our basic assumptions of this paper are as follows. Let the dust exposed on a bare soil surface be the available dust for aerodynamic entrainment. Then, the thoroughly disturbed soil possesses the maximum amount of available dust. As dust emission proceeds, supply limit for aerodynamic entrainment occurs when the available dust falls below a critical level. We define the replenishment of available dust as surface renewal. Therefore, saltation and creep enable surface renewal in several ways: (1) remove particles on the surface to expose the underlying dust, (2) spear into the soil to dislodge the dust initially not available and (3) blast onto aggregates and break them to release new surface dust. Surface renewal does not directly cause dust emission but it does recover surface available dust, which is the main difference from a normal saltation bombardment mechanism. The total emitted dust is divided into two parts: one part is attributed to aerodynamic entrainment $\left(F_{\mathrm{a}}\right)$ and the other to sandblasting $\left(F_{\mathrm{b}+\mathrm{c}}\right.$, including the contribution of saltation bombardment, $F_{\mathrm{b}}$, and aggregates disintegration, $F_{\mathrm{c}}$ ).

\section{Wind tunnel experiment}

We conducted the experiments in the wind tunnel of Lanzhou University. This open-return blow-down low-speed wind tunnel is $22 \mathrm{~m}$ long (only for work section) with a cross section of $1.3 \mathrm{~m}$ wide and $1.45 \mathrm{~m}$ high. The operational wind speed can be adjusted in the range of $4-40 \mathrm{~m} \mathrm{~s}^{-1}$. The wind tunnel has excellent performance in simulating atmospheric boundary-layer flows for near-surface wind environment studies. The detailed information of the wind tunnel can be found in Zhang et al. (2014).

\subsection{Experimental setup}

The setup for the experiments is as shown in Fig. 1. Roughness elements are placed $6 \mathrm{~m}$ upstream from the working section to initiate a turbulent boundary layer. Their heights are adjusted to ensure a logarithmic wind profile (up to $20 \mathrm{~cm}$ above ground) in the downstream measurement area under all applied flow speeds. A test surface is located immediately downstream of the roughness elements, which is $9 \mathrm{~m}$ long, $1 \mathrm{~m}$ wide and $5 \mathrm{~cm}$ deep and is paved with a soil. For measuring saltation, a sand trap is installed $8 \mathrm{~m}$ downstream from the frontal edge of the test surface. Two dust concentration probes are placed at 7 and $14 \mathrm{~cm}$ above the surface, each connected to a 1.109 Grimm aerosol spectrometer (Grimm Aerosol Technik GmbH \& Co. KG). A Pitot tube is anchored to an adjustable frame for measuring the profile of the flow speed at 10 sampling points at 10, 15, 20, 30, 50, 70, 100, 130, 160 and $200 \mathrm{~mm}$ above the surface.

Farmland soil collected from Minqin in Gansu Province, China (natural soil hereafter), and natural sand collected from the Tengger Desert (natural sand hereafter) are used for the preparation of the test surfaces. Three land surfaces are tested as shown in Fig. 1. In setting 1 (S1), the natural soil is used for the entire test bed to simulate a farmland surface, on which supply limit may commonly occur. In setting 2 (S2), the first $4 \mathrm{~m}$ of the test bed is paved with the natural sand ahead of $5 \mathrm{~m}$ of natural soil, to examine how enhanced saltation affects dust emission with respect to $\mathrm{S} 1$. The $\mathrm{S} 2$ case corresponds to a desert-edge surface, on which saltation is sig- 


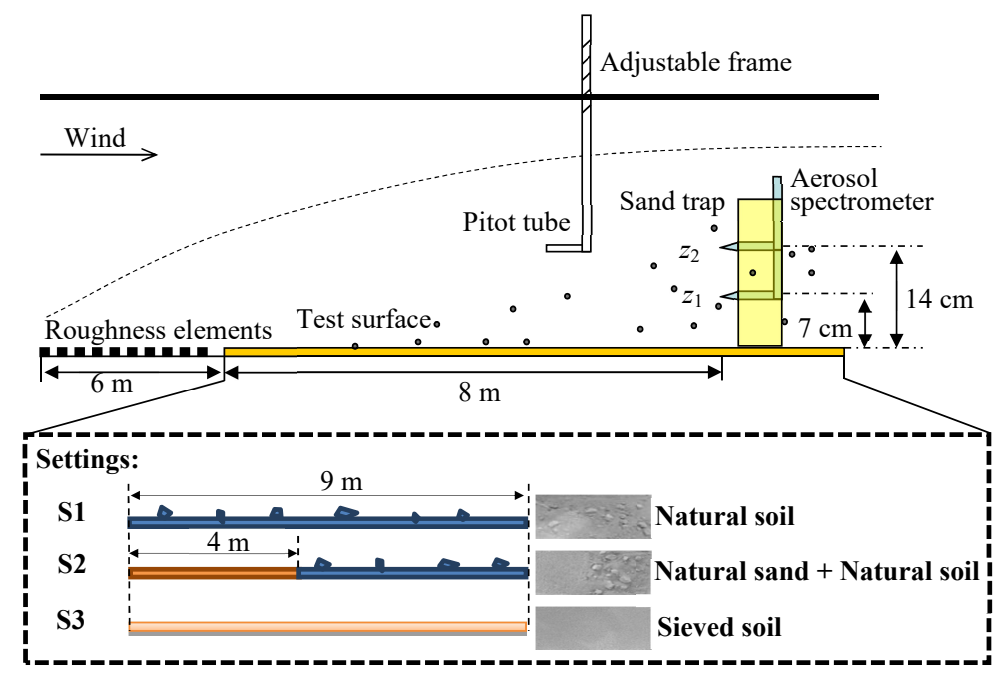

Figure 1. Wind tunnel configuration and simulated soil surfaces. The test surface of $9 \mathrm{~m}$ long, $1 \mathrm{~m}$ wide and $5 \mathrm{~cm}$ deep is located immediately downstream of the roughness elements. A position-adjustable Pitot tube is used to measure wind profile. A sand trap is installed $8 \mathrm{~m}$ downstream from the frontal edge of the test surface. Two GRIMM probes are fixed at 7 and $14 \mathrm{~cm}$ above the surface to measure dust concentration gradient.

nificant to cause dust emission. In setting 3 (S3), the natural soil is first sieved with a 20 mesh $(841 \mu \mathrm{m})$ sieve (sieved soil hereafter) and then paved to simulate a loess surface, which has sufficient dust content and low restriction for saltation.

\subsection{Instruments and measurements}

By regression of the Prandtl-von Kármán equation

$u(z)=\frac{u_{*}}{\kappa} \ln \left(\frac{z}{z_{0}}\right)$

to the Pitot-tube measurements, the friction velocity, $u_{*}$, and surface roughness, $z_{0}$, are estimated. In Eq. (9), $z$ is height, $u(z)$ is the mean flow velocity (over $3 \mathrm{~min}$ in our experiments) at height $z$ and $\kappa=0.4$ is the von Kármán constant.

The particle size distributions of the natural soil, natural sand and sieved soil were analyzed by using a Microtrac S3500 Laser Diffractometer (Microtrac, Montgomeryville, PA, USA) and approximated with an overlay of multiple lognormal distributions:

$d \times p(d)=\sum_{j=1}^{N} \frac{W_{j}}{\sqrt{2 \pi} \sigma_{j}} \exp \left[-\frac{\left(\ln d-\ln D_{j}\right)^{2}}{2 \sigma_{j}^{2}}\right]$,

where $N$ is the number of distribution modes $(N \leq 4), W_{j}$ is the weight of the $j$ th model of the particle size distribution and $D_{j}$ and $\sigma_{j}$ are the parameters in the $j$ th distribution. The particle size distribution of minimally disturbed soil $p_{\mathrm{m}}(d)$ and fully disturbed soil $p_{\mathrm{f}}(d)$ are measured similarly to Shao et al. (2011). The soil sample is dispersed in water and the resulting particle size distribution taken as $p_{\mathrm{m}}(d)$. The soil is first ground in a mortar and then be dispersed in $2 \%$ sodium hexametaphosphate to prepare the measurement for $p_{\mathrm{f}}(d)$. Although ultra-sonication is an effective method to break solid particles, the effect of chipping and attrition during particle collision does not occur during sonication which may result in wearing down individual particles and changing the size distribution. Therefore, the sonication step in Shao et al. (2011) is replaced with grinding in measuring $p_{\mathrm{f}}(d)$.

The saltation flux is measured using a sand trap adapted from the WITSEG sampler designed by Dong et al. (2003). Facing the wind stream are 38 stacked collectors $(2 \mathrm{~cm} \times 2 \mathrm{~cm}$ opening), each of which collects sand to its chamber. The streamwise saltation flux, $Q$, is then determined by weighing the sand in the chambers after each run:

$$
\begin{aligned}
Q & =\sum_{i=1}^{38} q_{i} \Delta h_{\mathrm{i}}, \\
q_{i} & =\frac{m_{\mathrm{i}}}{t_{\mathrm{s}} A_{\mathrm{i}}},
\end{aligned}
$$

where $\Delta h_{\mathrm{i}}$ is the vertical size of inlet for collector $i$ mounted at height $h_{\mathrm{i}}$ above the surface, $q_{i}$ is the saltation flux at $h_{\mathrm{i}}$, $m_{\mathrm{i}}$ is the mass of sand collected at $h_{\mathrm{i}}, t_{\mathrm{S}}$ is the time duration of sand collection and $A_{\mathrm{i}}$ is the inlet area of the collector.

Once emitted, dust is transported vertically by turbulent diffusion. Assuming steady state and horizontal homogeneity, the vertical diffusive flux is equal to dust emission flux and can be evaluated by the gradient method, which has been applied in previous wind tunnel studies on dust emission (Gillette et al., 1974; Fairchild and Tillery, 1982; Borrmann and Jaenicke, 1987). Our environmental wind tunnel is designed for simulating atmospheric boundary-layer flows and its performance has been validated by testing the pressure gradient and the stability of the wind profile along with 
Table 1. Runs for the dust emission experiments and the regression parameters for wind profiles over the three different surfaces. Four kinds of wind friction velocities are simulated for each surface. $R^{2}$ is determination coefficient of the regression.

\begin{tabular}{lrcccl}
\hline Surface & Runs & $\begin{array}{c}u_{*} \\
\left(\mathrm{~m} \mathrm{~s}^{-1}\right)\end{array}$ & $\begin{array}{c}z_{0} \\
(\mathrm{~mm})\end{array}$ & $R^{2}$ & Configuration \\
\hline \multirow{3}{*}{ S1 } & 1 & 0.34 & 0.15 & 0.98 & \\
& 2 & 0.38 & 0.13 & 0.99 & Natural soil \\
& 3 & 0.42 & 0.11 & 0.98 & \\
\hline \multirow{3}{*}{ S2 } & 4 & 0.44 & 0.09 & 0.99 & \\
& 5 & 0.35 & 0.15 & 0.99 & Natural soil \\
& 6 & 0.40 & 0.14 & 0.97 & + natural sand for \\
& 7 & 0.43 & 0.11 & 0.99 & bombardment \\
& 8 & 0.49 & 0.10 & 0.95 & \\
S3 & 9 & 0.23 & 0.02 & 0.97 & \\
& 10 & 0.33 & 0.10 & 0.98 & Sieved soil \\
& 11 & 0.37 & 0.09 & 0.99 & \\
\hline
\end{tabular}

streamline. We also tested the performance of this wind tunnel in simulating well-mixed dust cloud with an $8 \mathrm{~m}$ fetch in a previous study on dust deposition (Zhang, 2013). Thus, the condition of our laboratory satisfies the requirements of the gradient method. In our experiments, dust concentration, $C$, is measured at $z_{1}=7 \mathrm{~cm}$ and $z_{2}=14 \mathrm{~cm}$ above the surface, and thus the dust emission rate can be calculated as

$F=-K_{\mathrm{p}} \frac{C\left(z_{2}\right)-C\left(z_{1}\right)}{z_{2}-z_{1}}$,

where $K_{\mathrm{p}}$ is the turbulent diffusion coefficient for dust particles, which can be approximated as

$K_{\mathrm{p}}=K_{\mathrm{m}}=u_{*} l$,

where $l$ is the mixing length, taken here as $\kappa\left(z_{1}+z_{2}\right) / 2$. Except for the requirement of the experimental condition mentioned above; therefore, dust particles should be small enough, then the gravitational settling can be ignored and Eq. (14) is applicable. Normally, this method works for particles with a diameter smaller than $20 \mu \mathrm{m}$ (Gillette et al., 1972; Sow et al., 2009; Shao et al., 2011).

\subsection{Procedures of wind tunnel experiments}

The wind tunnel experiments are carried out according to the settings given in Table 1 and the following procedures:

1. prepare soil and pave test bed as shown in Fig. 1;

2. set up instruments as shown in Fig. 1;

3. set fan to target flow speed, measure dust concentration and wind speed over $10 \mathrm{~min}$ and end run early if test bed is blown bare or sand chambers are filled;

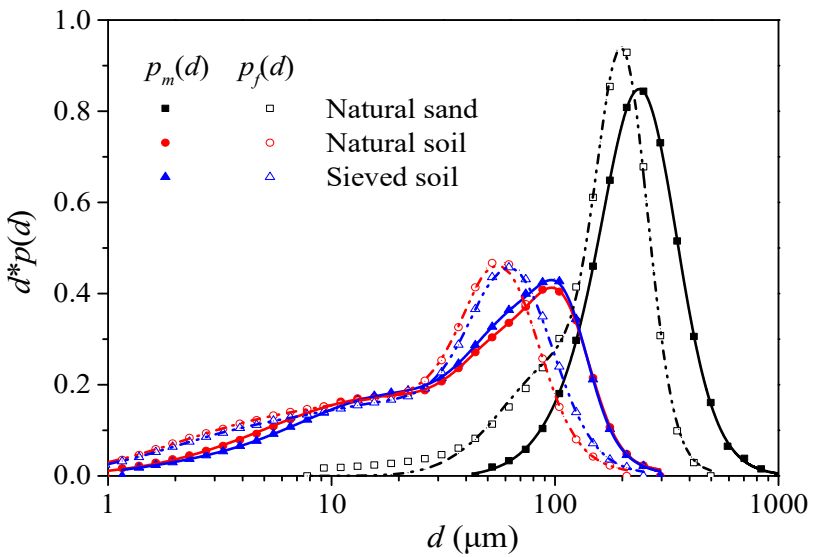

Figure 2. Minimally and fully disturbed particle size distributions of the source materials, which are used to simulated the three surfaces illustrated in Fig. 1, namely, the natural sand, natural soil and sieved soil. The dots represent the measured values, while the lines represent Eq. (10) fitted to the measurements. The fitting parameters are shown in Table 2.

4. turn off fan, record time duration for saltator collection; weigh mass of collected saltators and save dust concentration data measured with aerosol spectrometer;

5. restart fan set to the same target speed as step 3, and measure wind profile;

6. remove paved soil (soil must not be reused because emission has changed dust content) and start over from step 1 for next run.

\section{Results and analysis}

\subsection{Particle size distribution of source materials and wind profiles}

The particle size distributions of the natural soil, natural sand and sieved soil are shown in Fig. 2. The dots represent the measured values, while the lines in Eq. (10) fitted to the measurements (see Table 2 for fitting parameters). For the natural sand, the fraction of particles in the size range of 10 $200 \mu \mathrm{m}$ increases due to grinding, while for the natural soil and sieved soil the increased fractions are relevant to the size ranges of $1-10$ and $30-60 \mu \mathrm{m}$.

The natural soil contained many lumps (diameter in centimeter scale) that can be easily broken by external impact or abrasion. These lumps disperse in water and thus the similarity in $p_{\mathrm{m}}(d)$ between the natural and sieved soils does not reflect the existence of the large lumps in the natural soil. However, the lumps may significantly influence dust emission by causing spatial shear stress variations and by sheltering the surface from erosion. It was also found that the soil lumps were easily destroyed during the sieving process and 

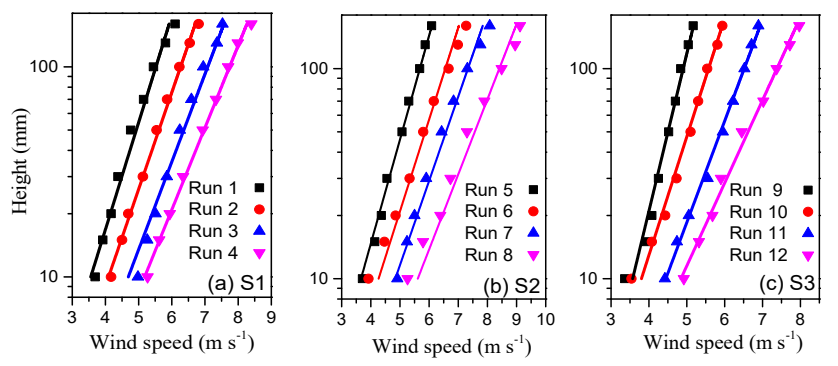

Figure 3. Wind profiles over three different surfaces. The dots are experimental data and the lines are regression curves from Eq. (9). The regression parameters are listed in Table 1.

the characterization of large soil lumps remains a problem to be better solved in future research.

The wind velocities measured in the height range of 10 $160 \mathrm{~mm}$ (the data obtained at the topmost measurement point are erratic and therefore not included) are shown in Fig. 3. The dots are averaged wind speeds over 3 min measured with Pitot tubes and the lines are the regressions using Eq. (9). As shown, the profiles of the horizontal wind velocity follow the logarithmic law and can be fitted with the Prandtl-von Kármán equation very well. The values of the regression parameters are listed in Table 1.

\subsection{Streamwise saltation flux}

The measured streamwise saltation fluxes are shown in Fig. 4. For all three surfaces, saltation flux increased with friction velocity, but the saltation flux of S2 (natural soil surface under sand bombardment) was significantly larger than that of S1 (natural soil surface) by more than an order of magnitude, due to the impact of saltating sand particles. No saltation was detected over S1 and S2 for $u_{*}<0.34 \mathrm{~m} \mathrm{~s}^{-1}$, but over $\mathrm{S} 3$, significant saltation was measured for $u_{*}>0.23 \mathrm{~m} \mathrm{~s}^{-1}$. For $u_{*}>0.35 \mathrm{~m} \mathrm{~s}^{-1}$, the saltation flux of S3 obviously exceeded that of S1, but is smaller than that of S2.

It is first necessary to validate the formulations of streamwise saltation flux, which is closely related to most dust emission models (e.g., LS99, S04). In the case of saltation of uniform particles, saltation flux can be estimated using the Owen model (i.e., Eq. 8), but $c_{0}$ and $u_{*_{t}}$ are tuneable parameters to be determined by regression to the observations. The model-simulated results are shown in Fig. 4 (regression 1, dotted curves) together with the regression parameters $c_{0}$ and $u_{*_{t}}$ and determination coefficient, $R^{2}$. As $c_{0}$ is related to the terminal velocity of the saltating particles, it is obviously big for S2 (corresponding to big sand particles). $u_{*_{t}}$ is effected by the size of soil particles and surface roughness, and is therefore large for S1 (because of high surface roughness) and for S2 (because of big size of sand particles).

The above fitting is straightforward and gives reasonable results except for the cases when the friction velocity is close to the threshold friction velocity. An alternative method is to calculate the saltation fluxes for different particle size bins by Eq. (8) and then integrate over the size bins to obtain the total saltation flux

$$
Q=\int_{d_{1}}^{d_{2}} Q\left(d_{\mathrm{s}}\right) p\left(d_{\mathrm{s}}\right) \delta d_{\mathrm{s}} .
$$

The threshold friction velocity is evaluated by (Shao and $\mathrm{Lu}$, 2000)

$$
u_{*_{t}}\left(d_{\mathrm{S}}\right)=\sqrt{A_{n}\left(\sigma_{\varphi} g d_{\mathrm{s}}+\frac{r}{\rho d_{\mathrm{S}}}\right)},
$$

where $A_{n}$ and $r$ are the regression parameters. The threshold friction velocities calculated using Eq. (16), together with the regression parameters $A_{n}$ and $r$, are shown in Fig. 4. It is seen that the second method (regression 2, solid curves) gives a more accurate estimate of $Q$ than the first (regression 1), and the threshold friction velocity appears to be influenced by not only particle size but also surface conditions, as the different values of $A_{n}$ and $r$ imply. As shown in the inserted graph of Fig. 4, the surmised curves of threshold friction velocity are different from the conventional threshold curve with a minimum around $100 \mu \mathrm{m}$ (Fletcher, 1976a, b; Greeley and Iversen, 1985; Shao and Lu, 2000). This divergence may be caused by saltation bombardment, which may change the rule of threshold for different particles. Additionally, surface obstacles (such as lumps in S1 and S2) may also affect surface particle threshold by absorbing momentum and generating turbulent eddies.

It should be noted that for S1 and S3, the simulated surface is $8 \mathrm{~m}$ long in addition to the $6 \mathrm{~m}$ roughness section, and therefore the saltation of soil particles should have been saturated, but not for $\mathrm{S} 2$ for which the simulated sand surface is only $4 \mathrm{~m}$ in length (Shao and Raupach, 1992; Rasmussen et al., 2015). For the unsaturated sand saltation, the particle speeds would increase with increased $u_{*}$ (Ho et al., 2011; Kok, 2011), which may cause the bombardment efficiency to increase.

\subsection{Vertical dust flux}

Vertical dust fluxes can be calculated with Eqs. (13) and (14) using the measured dust concentrations at the levels of 7 and $14 \mathrm{~cm}$. In this study, dust is defined as particles with diameter smaller than $15 \mu \mathrm{m}$ to satisfy the requirement of the gradient method. It can be seen from Fig. 5 that for S1, dust emission has an initial sharp increase followed by a rapid decline (Fig. 5a). The same phenomenon has been reported in earlier studies and is considered to be characteristic of aerodynamic entrainment under limited supply of free dust (Shao et al., 1993; Loosmore and Hunt, 2000). After 3 min, the vertical dust flux tends to be stable. Therefore, we calculated the average dust flux over the interval of 3 to $10 \mathrm{~min}$ (dashed lines 
Table 2. Lognormal distribution parameters for the three kinds of soils used in the experiments. $d$ is particle diameter, $W_{j}$ is the weight of the $j$ th distribution, $D_{j}$ and $\sigma_{j}$ are the parameters in the $j$ th distribution and $j(\leq 4)$ refers to $j$ th model.

\begin{tabular}{|c|c|c|c|c|c|c|c|c|c|c|c|c|c|}
\hline \multirow[t]{2}{*}{ Material } & & \multicolumn{3}{|c|}{ Mode 1} & \multicolumn{3}{|c|}{ Mode 2} & \multicolumn{3}{|c|}{ Mode 3} & \multicolumn{3}{|c|}{ Mode 4} \\
\hline & & $W_{1}$ & $\ln \left(D_{1}\right)$ & $\sigma_{1}$ & $W_{2}$ & $\ln \left(D_{2}\right)$ & $\sigma_{2}$ & $W_{3}$ & $\ln \left(D_{3}\right)$ & $\sigma_{3}$ & $W_{4}$ & $\ln \left(D_{4}\right)$ & $\sigma_{4}$ \\
\hline \multirow{2}{*}{ Sand } & $p_{\mathrm{m}}(d)$ & 0.471 & 5.51 & 0.34 & 0.529 & 5.34 & 0.54 & & & & & & \\
\hline & $p_{\mathrm{f}}(d)$ & 0.570 & 5.31 & 0.26 & 0.430 & 4.70 & 0.60 & & & & & & \\
\hline \multirow{2}{*}{ Natural soil } & $p_{\mathrm{m}}(d)$ & 0.196 & 4.70 & 0.29 & 0.229 & 4.42 & 0.43 & 0.575 & 2.88 & 1.23 & & & \\
\hline & $p_{\mathrm{f}}(d)$ & 0.357 & 4.06 & 0.37 & 0.314 & 3.44 & 0.86 & 0.329 & 1.73 & 1.06 & & & \\
\hline \multirow{2}{*}{ Sieved soil } & $p_{\mathrm{m}}(d)$ & 0.109 & 4.72 & 0.24 & 0.372 & 4.31 & 0.49 & 0.488 & 2.95 & 1.02 & 0.031 & 0.88 & 0.70 \\
\hline & $p_{\mathrm{f}}(d)$ & 0.408 & 4.17 & 0.41 & 0.364 & 3.29 & 0.92 & 0.228 & 1.49 & 0.94 & & & \\
\hline
\end{tabular}

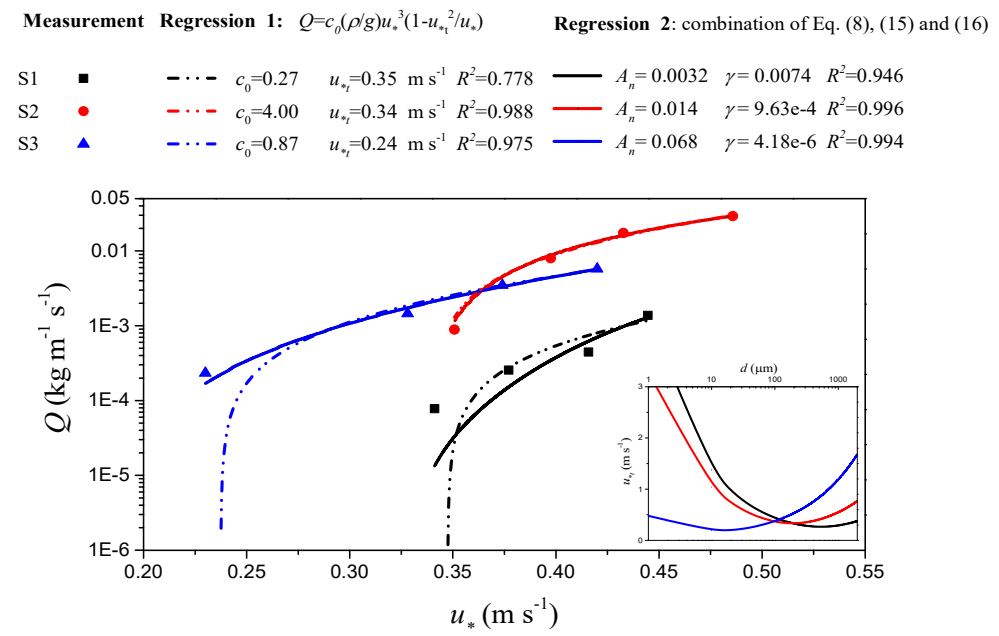

Figure 4. Streamwise saltation flux over the three soil surfaces tested in the wind tunnel experiment. The symbols are experimental data. The dot-dashed lines are regressions with Eq. (8); $c_{0}$ and $u_{*_{t}}$ are treated as regression parameters. The solid lines correspond to the combinations of Eqs. (8), (15) and (16). $A_{n}$ and $r$ are the regression parameters, which determine the friction velocities shown in the inserted graph.

in Fig. 5) for all cases and plotted the results in Fig. 6 (triangles). For comparison, the data of LH2000 and MP2008 are plotted as circles and squares, respectively. As shown, our results are comparable with MP2008 but obviously greater than LH2000. Generally, dust vertical fluxes increase with friction velocity by following a power function. But the results for the three surfaces differ by several orders of magnitudes.

By considering that $\mathrm{S} 1$ resembled the unperturbed surface in MP2008, whereas S2 and S3 the renewed surface in MP2008, the S2 surface was indeed renewed by external sand bombardment and the $\mathrm{S} 3$ by the spontaneous saltation and creep of big particles. Thus, the dust emission of $\mathrm{S} 2$ was about 1 order of magnitude larger than that of $\mathrm{S} 1$ because the former experienced stronger saltation bombardment. The dust flux of S3 was another order of magnitude larger than that of $\mathrm{S} 1$ because of the higher dust content at the surface.

In our experiments, paving the test bed caused mechanical disturbances to the soil. Thus, at the beginning of the run, the amount of free dust available for aerodynamic entrainment should be close to the maximum for the given soil. As dust emission continued, the amount of available free dust thus was gradually depleted and eventually exhausted. That appears to be a reasonable explanation of the phenomenon that occurred in $\mathrm{S} 1$ in the first $3 \mathrm{~min}$. After about $3 \mathrm{~min}$, dust emission was mainly attributed to weak saltation bombardment (Fig. 5a). We therefore separate the time series into the two sections of $0-3$ and $3-10 \mathrm{~min}$. The vertical dust flux averaged over the $0-3$ min section, $F_{0-3 \min }$, is the dust emission due to both aerodynamic entrainment and saltation bombardment with unlimited dust supply. The dust flux averaged over the 3-10 min section, $F_{3}-10 \min \left(F_{\mathrm{b}}\right)$, is the dust emission due to saltation bombardment under limited dust supply (here, the effect of aggregates disintegration is not discussed individually and the related contribution is involved in $F_{\mathrm{b}}$ ). Based on the theory of dust emission described in Sect. 2, dust emission via aerodynamic entrainment depends on the amount of exposed surface dust, and saltation bombardment dust relates to the dust content of the subsurface. For the case without surface renewal (S1), as result of dust emission, the exposed surface dust was exhausted and a supply limit occurred. But 

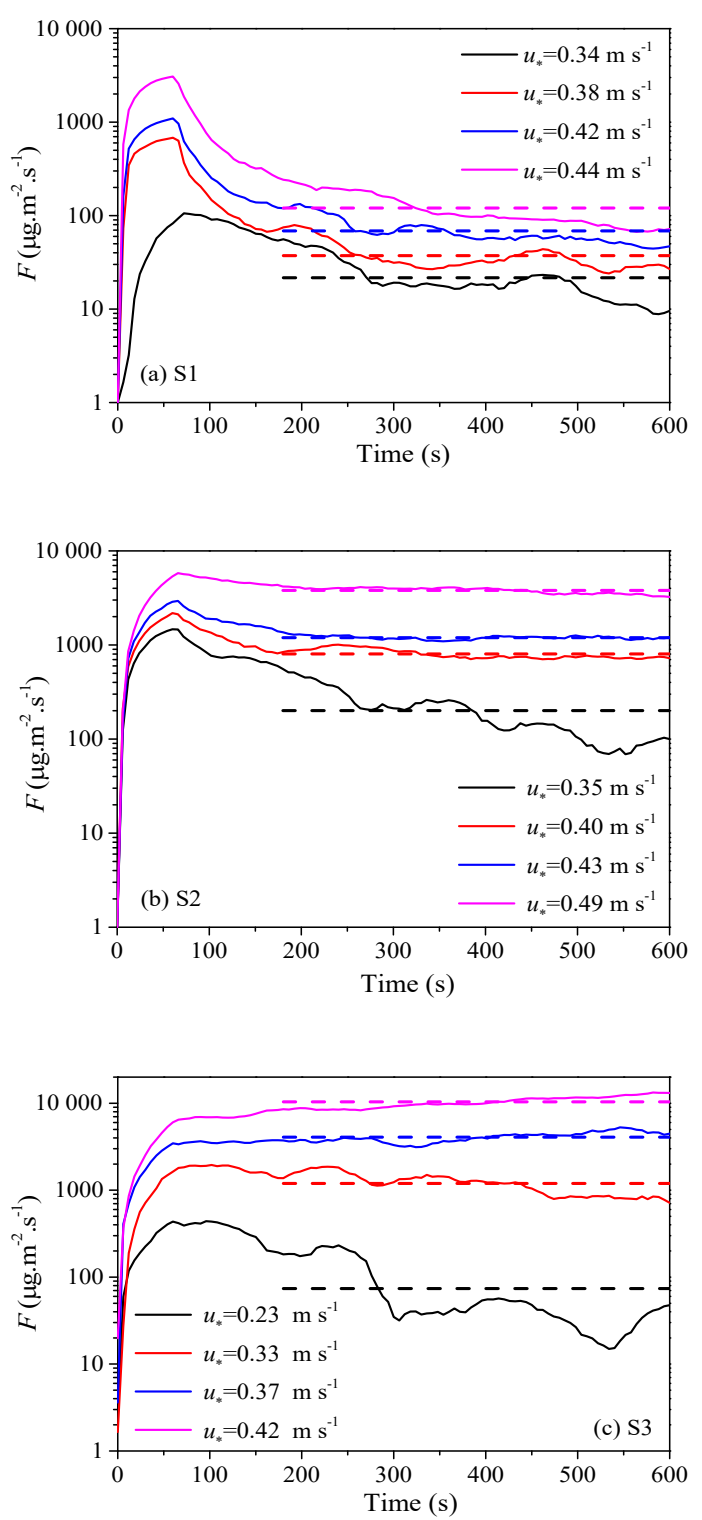

Figure 5. Vertical dust flux series over the three surfaces tested in the wind tunnel experiment. The dashed lines represent average values form 3 to $10 \mathrm{~min}$.

the dust content of the subsurface should not have changed significantly during the measurement time of $10 \mathrm{~min}$, due to the lack of motion of large surface particles that renew the surface. So it is reasonable to assume that there was no significant difference in dust emission via saltation bombardment during the measurement time, and the difference between the average vertical dust fluxes over the first $3 \mathrm{~min}\left(F_{0-3 \min }\right)$ and over the last $7 \mathrm{~min}\left(F_{3-10 \mathrm{~min}}\right)$ is therefore considered as the dust emission caused by aerodynamic entrainment $\left(F_{\mathrm{a}}\right)$ under unlimited dust supply (Fig. 6, pentagram dots).

In contrast, S2 and S3 did not show such a remarkable decrease of dust flux after the initial phase, probably due to the intensive saltation (see Fig. 4), which timely replenished the dust supply. But in general, it is not possible to separate the contributions due to aerodynamic entrainment and saltation bombardment. We have noted that the comparable saltation flux over S1 did not lead to surface renewal as it did over S3. This shows that surface renewal is affected both by saltation intensity and surface properties (i.e., $\mathrm{S} 1$ is more resistant to be renewed).

The results show that the dust flux due to aerodynamic entrainment in S1 under unlimited supply was far greater than that in LH2000 (Fig. 5) and the maximum value $\left(F_{\mathrm{a} \mid \max }\right.$, which is about 3 times the average flux) even exceeded the dust flux due to strong saltation bombardment in S2. This may be due to the uneven distribution of surface shear over the rough surface in S1. Thus, we conclude that flow conditions, surface particle motion, dust availability and surface roughness can jointly cause dust fluxes to differ by orders of magnitudes.

The measured dust fluxes averaged over the period of $3-$ $10 \mathrm{~min}$ are then examined with regression analysis. Equation (3) is chosen as the regression equation and the regression curves are shown as solid lines in Fig. 6. For S1, the natural soil with weak saltation bombardment had a dust flux proportional to $u_{*}^{4}$, in agreement with Gillette and Passi (1988). The introduction of saltation bombardment in $\mathrm{S} 2$ increased dust emission by 1 order of magnitude, with dust flux proportional to $u_{*}^{6}$. In S3, dust flux increased by 2 orders of magnitude compared to S1, with dust flux proportional to $u_{*}^{7}$. But under unlimited supply in $\mathrm{S} 1$, the dust flux was proportional to $u_{*}^{10}$, if the threshold friction velocity is set to the same value as in the case of S1 with the period of 3-10 min (i.e., $u_{*-t}=0.29 \mathrm{~m} \mathrm{~s}^{-1}$ ). The regression analysis shows that with intensified surface renewal from S1 to S3, the relationship between dust flux and friction velocity increasingly resembled the aerodynamic entrainment under unlimited supply. An interpretation of this could be that strong saltation bombardment and creep enabled surface renewal, thereby removing supply limit and maintaining dust emission at a high level. From this point of view, dust emission can be considered to be driven by a combination of aerodynamic entrainment and saltation bombardment. Considering that saltation and creep are responsible for surface renewal, which restores the availability of dust for emission, the contribution of aerodynamic entrainment should not be ignored and may be dominant under some conditions.

To test the above hypothesis, the total dust vertical flux is considered as the sum of two parts:

$F=F_{\mathrm{a}}+F_{\mathrm{b}+\mathrm{c}}=c_{1} \cdot u_{*}^{10}\left(1-\frac{u_{*_{t}}}{u_{*}}\right)+c_{2} \cdot u_{*}^{4}\left(1-\frac{u_{*_{t}}}{u_{*}}\right)$,

where $c_{1}$ relates to exposed dust content and $c_{2}$ to subsurface dust content and impact energy of saltators. The first term on the right-hand side of Eq. (17) is attributed to aerodynamic entrainment and the second to saltation bombardment and aggregates disintegration. We now use Eq. (17) to predict the vertical dust fluxes over the different surfaces. The values of 


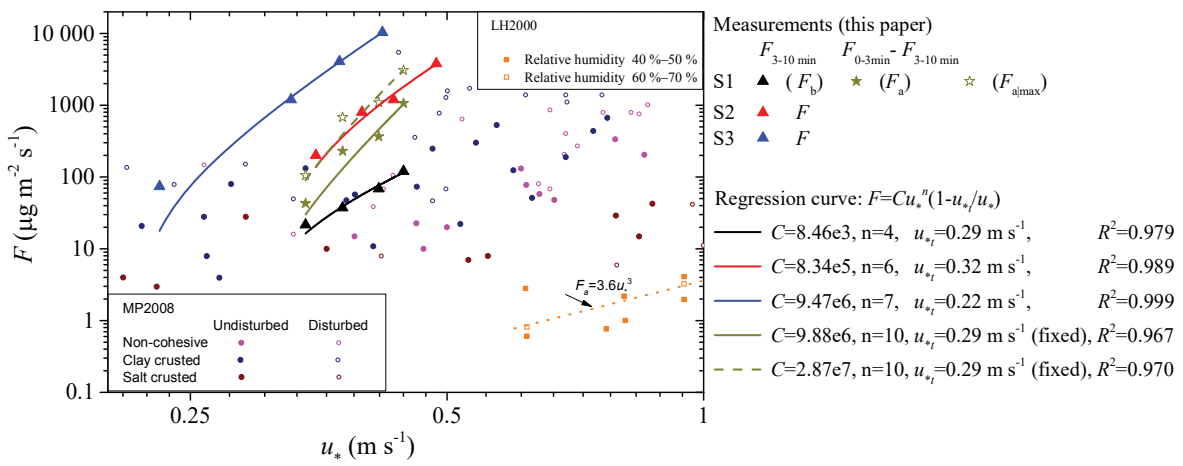

Figure 6. Measured vertical dust fluxes over the three different surfaces in the wind tunnel experiment (triangles), together with the measurements of Loosmore and Hunt (2000) and Macpherson et al. (2008), respectively labeled as LH2000 and MP2008, as well as the various regression curves.

$u_{*_{t}}$ are assumed to be the same as in Fig. 6, and $c_{1}$ and $c_{2}$ are obtained by regression analysis. As shown in Fig. 7, Eq. (17) can well describe the experimental data, and based on the estimated values of $c_{1}$ and $c_{2}$, the ratio of $F_{\mathrm{a}} / F$ can be readily estimated, as shown in Fig. 7 (dashed lines). It is seen that, sometimes (e.g., high $u_{*}$ over S2 and S3) the contribution of aerodynamic entrainment can exceed saltation bombardment $\left(F_{\mathrm{a}} / F>0.5\right)$ and be the dominate mechanism for dust emission. It appears that saltation not only causes dust emission but also surface renewal, which restores the availability of dust for the emission.

\subsection{Bombardment efficiency}

Bombardment efficiency, $\eta=F / Q$, (Gillette, 1979; Marticorena and Bergametti, 1995; Shao, 2008; Macpherson et al., 2008) is a key parameter for the saltation bombardment process. Previous studies suggested that dust emission is mainly due to saltation bombardment and for a given surface $\eta$ appears to be a relatively stable constant (Marticorena and Bergametti, 1995; Houser and Nickling, 2001). Others found that $\eta$ increases with $u_{*}$ (Nickling et al., 1999; Kok et al., 2012) and this increase depends on surface conditions (Shao, 2001). However, measurements are so far insufficient to verify this theory. In MP2008 (Macpherson et al., 2008), as the surface conditions were very complex, the measured bombardment efficiency scattered over a range of 4 orders of magnitude and did not show a fixed relationship with friction velocity.

The bombardment efficiencies we measured are shown as dots in Fig. 8. It is observed that around the threshold friction velocity for each setting, $\eta$ ranged between 2.0 and $3.0 \times 10^{-4} \mathrm{~m}^{-1}$, which is close to the result of MP2008. However, it behaved differently as $u_{*}$ increased. In S1, it decreased exponentially with $u_{*}$. But in S2, $\eta$ first decreased and then increased with increasing $u_{*}$. For the case of S3, it monotonically increased with $u_{*}$.

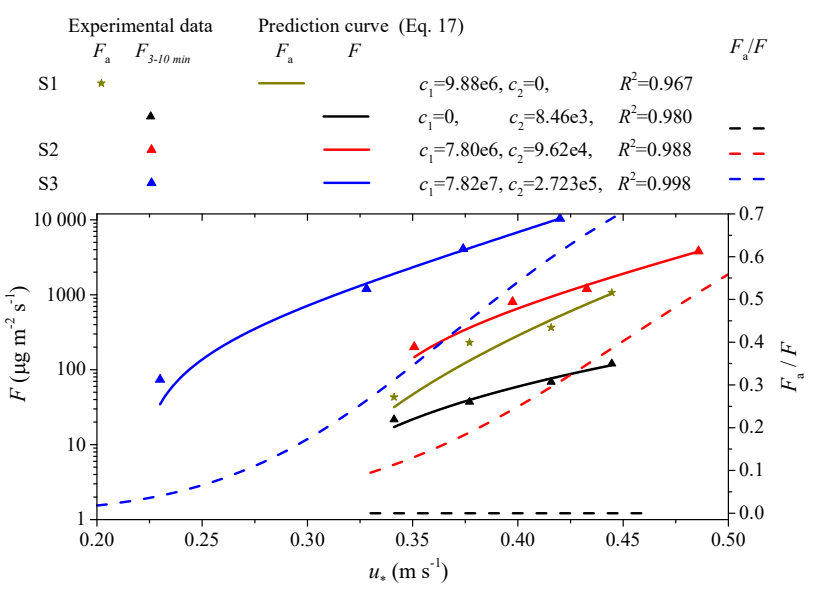

Figure 7. Predictions of Eq. (17) and the predicted contribution of aerodynamic entrainment $F_{\mathrm{a}}$ is illustrated as the dashed lines with the right vertical coordinate. $u_{*_{t}}$ is valued as in Fig. 6 . The solid lines and symbols are the same as in Fig. 6 .

We now analyze the possible reasons for the behavior of $\eta$. In $\mathrm{S} 1$, the decrease cannot be explained using the existing dust emission modes (Lu and Shao, 1999; Shao, 2001, 2004). It is likely that as saltation bombardment was weak in $\mathrm{S} 1$ and could only lift the dust in a thin soil layer. Once the dust in this thin layer was depleted, the surface became dust supply limited. In S2, with the increase of $u_{*}$, the large number of saltators from the upstream may have buried the dust on the surface of the test bed and changed its properties, thus leading to the decline in bombardment efficiency similar to $\mathrm{S} 1$. As $u_{*}$ further increased, the sand particles would not settle on the test bed, but continue to strike the surface and expose more dust to air, thus increasing the bombardment efficiency. It implies that the degree of surface renewal may significantly affect the bombardment efficiency. In S3, the available dust content is high and the bombardment efficiency is much higher than that in S1 and S2. The sieved 


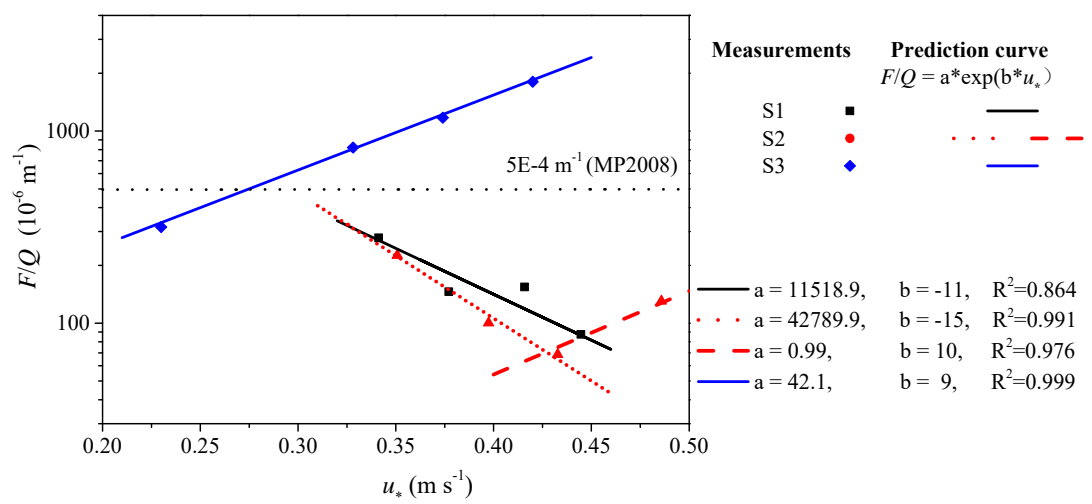

Figure 8. The ratio of dust emission to streamwise saltation flux. The symbols are experimental results, and the lines are prediction curves with the equation shown in the legend.

soil used in $\mathrm{S} 3$, free from the sheltering of the lumps, is very mobile. Thus, as wind speed increased, the sieved soil particles may undertake strong bombardment over the surface and enhanced surface renewal. This allows for an unlimited dust supply to maintain the bombardment efficiency. But even this does not seem to explain the increase of $\eta$ with an exponent of $u_{*}$ (blue line in Fig. 8). While the decline of $\eta$ with $u_{*}$ in S1 and the preceding stage of S2 may be due to the inadequate replenishment of dust supply, the increase of $\eta$ with $u_{*}$ in S3 and the last stage of S2 must be due to the contribution of aerodynamic entrainment, which appears to be in line with the previous discussion of Fig. 7. We also note that the increase rate of $\eta$ with $u_{*}$ in the last stage of S2 is slight higher than that of S3. This could be caused by the unsaturated sand saltation in which the velocity of saltating particle may increase with $u_{*}$ (Ho et al., 2011; Kok, 2011) and thus the bombardment efficiency increases.

In short, we conclude that the strong saltation bombardment enabled surface renewal and dust supply to maintain saltation bombardment efficiency; if the surface renewal is inadequate, then $\eta$ decreases with $u_{*}$; in contrast, if the saltation and creep generate sufficient surface renewal and hence dust supply, then $\eta$ increases with $u_{*}$.

\section{Conclusions}

Three soil surfaces, representing farmland, desert edge and loess, were tested in a wind tunnel experiment to examine the dust emission mechanisms. It has been found that

1. Flow conditions, saltation bombardment, surface dust content and ground obstacles may all significantly affect dust emission, causing dust emission to change over orders of magnitude.

2. Dust emission due to aerodynamic entrainment from the natural soil surface is proportional to $u_{*}^{10}$, if the supply of free dust is unlimited, as in the initial phase (typically the first $2-3 \mathrm{~min}$ ) of the wind tunnel runs. This shows that in general, aerodynamic entrainment can be an important (even a dominant) process for dust emission under certain circumstances.

3. Supply limit appears to be the major reason to restrict dust emission. In nature, dust emission may be often supply limited and hence the contribution of aerodynamic entrainment is determined by the renewal of the surface, which results in increased availability of free dust for emission.

4. Surface renewal through saltation and creep of surface particles should be the major pathway to ease the supply limit for dust emission. Surface renewal is not only important to the availability of dust for aerodynamic entrainment, but also important to the efficiency of saltation bombardment, $\eta$. It is shown that $\eta$ depends on friction velocity, and the dependency differs for different surfaces reliant on the process of surface renewal.

Dust emission seems to be a process driven by fluid motion and restricted by dust supply. The saltation and creep of large particles can generate surface renewal and restore the dust supply. Thus, the contribution of aerodynamic entrainment cannot be overlooked and the processes of supply limitation and surface renewal must be given due attention. Our experiment has shown that aerodynamic entrainment is highly efficient when dust supply is sufficient. Since surface renewal often does not fully liberate the potential of aerodynamic entrainment, dust emission in general can be seen as limited aerodynamic entrainment, and the extent of restriction depends on the degree of surface renewal.

This study does not contradict the earlier perception that saltation plays a fundamentally important role in dust emission because saltation not only generates bombardment emission and aggregates disintegration but also provides power for creep and contributes directly or indirectly to surface renewal. What is new in this paper is that we have been able to demonstrate the importance of surface renewal to aerodynamic entrainment in dust emission process. 
In addition to the surface renewal by saltation and creep, or dynamic surface renewal, other processes, such as dust deposition and weathering, also contribute to surface renewal. Further experimental observations and theoretical analysis are necessary to establish a general surface renewal model.

\section{Data availability}

The underlying data can be found in the Supplement.

\section{The Supplement related to this article is available online at doi:10.5194/acp-16-15517-2016-supplement.}

Acknowledgements. This work is supported by the State Key Program of National Natural Science Foundation of China (91325203), the National Natural Science Foundation of China (41371034, 11602100), the Innovative Research Group of the National Natural Science Foundation of China (11421062), the Fundamental Research Funds for the Central Universities (lzujbky-2014-1) and the Hebei Province Department of Education Fund (QN2014111).

Edited by: L. M. Russell

Reviewed by: two anonymous referees

\section{References}

Alfaro, S. C. and Gomes, L.: Modelling mineral aerosol production by wind erosion: Emission intensities and aerosol size distributions in source areas, J. Geophys. Res., 106, 18075-18084, 2001.

Borrmann, S. and Jaenicke, R.: Wind tunnel experiments on the resuspension of sub-micrometer particles from a sand surface, Atmos. Environ., 21, 1891-1898, 1987.

Dong, Z., Sun, H., and Zhao, A.: WITSEG sampler: a segmented sand sampler for wind tunnel test, J. Dust Res., 23, 714-720, 2003.

Fairchild, C. and Tillery, M.: Wind tunnel measurements of the resuspension of ideal particles, Atmos. Environ., 16, 229-238, 1982.

Fletcher, B.: The erosion of dust by an airflow, J. Phys. D, 9, 913924, 1976a.

Fletcher, B.: The incipient motion of granular materials, J. Phys. D, 9, 2471-2478, 1976b.

Gillette, D. A.: On the production of soil wind erosion aerosols having the potential for long range transport, Journal de Recherches Atmospheriques, 8, 735-744, 1974.

Gillette, D. A.: Fine particulate emissions due to wind erosion, T. ASAE, 20, 890-987, 1977.

Gillette, D. A.: Environmental factors affecting dust emission by wind erosion, Saharan Dust, John Wiley, New York, 71-94, 1979.

Gillette, D. A.: Production of dust that may be carried great distances, Spec. Pap. Geol. Soc. Am., 186, 11-26, 1981.

Gillette, D. A. and Passi, R.: Modeling dust emission caused by wind erosion, J. Geophys. Res., 93, 14233-14242, 1988.
Gillette, D. A., Blifford, I. H., and Fenster, C. R.: Measurements of Aerosol Size Distributions and Vertical Fluxes of Aerosols on Land Subject to Wind Erosion, J. Appl. Meteorol., 11, 977-987, 1972.

Greeley, R. and Iversen, J. D.: Wind as a Geological Process on Earth, Mars, Venus, and Titan, Cambridge University Press, New York, 1985.

Ho, T. D., Valance, A., Dupont, P. and Ould El Moctar, A.: Scaling laws in aeolian sand transport, Phys. Rev. Lett., 106, 265-270, 2011.

Houser, C. A. and Nickling, W. G.: The emission and vertical flux of particulate matter $<10 \mu \mathrm{m}$ from a disturbed clay-crusted surface, Sedimentology, 48, 255-267, 2001.

Kjelgaard, J., Chandler, D., and Saxton, K. E.: Evidence for direct suspension of loessial soils on the Columbia Plateau, Earth Surf. Proc. Land., 29, 221-236, 2004.

Klose, M. and Shao, Y.: Stochastic parameterization of dust emission and application to convective atmospheric conditions, Atmos. Chem. Phys., 12, 7309-7320, doi:10.5194/acp-12-73092012, 2012.

Kok, J. F.: Does the size distribution of emitted dust aerosols depend on the wind speed at emission?, Atmos. Chem. Phys., 11, 1014910156, doi:10.5194/acp-11-10149-2011, 2011.

Kok, J. F., Parteli, E. J. R., Michaels, T. I., and Karam, D. B.: The physics of wind-blown sand and dust, Rep. Prog. Phys., 75, 106901, doi:10.1088/0034-4885/75/10/106901, 2012.

Kok, J. F., Mahowald, N. M., Fratini, G., Gillies, J. A., Ishizuka, M., Leys, J. F., Mikami, M., Park, M.-S., Park, S.-U., Van Pelt, R. S., and Zobeck, T. M.: An improved dust emission model - Part 1: Model description and comparison against measurements, Atmos. Chem. Phys., 14, 13023-13041, doi:10.5194/acp14-13023-2014, 2014.

Loosmore, G. A. and Hunt, J. R., Dust resuspension without saltation, J. Geophys. Res., 105, 20663-20671, doi:10.1029/2000JD900271, 2000.

Lu, H. and Shao, Y.: A new model for dust emission by saltation bombardment, J. Geophys. Res., 104, 16827-16842, 1999.

Macpherson, T., Nickling, W. G., Gillies, J. A., and Etyemezian, V.: Dust emissions fromundisturbed and disturbed supply-limited desert surfaces, J. Geophys. Res., 113, F02S04, doi:10.1029/2007JF000800, 2008.

Marticorena, B. and Bergametti, G.: Modelling the atmospheric dust cycle: 1. Design of a soil-derived dust emission scheme, J. Geophys. Res., 100, 16415-16430, 1995.

Nickling, W. G., McTainsh, G. H., and Leys, J. F.: Dust emissions from the Channel Country of western Queensland, Australia Zeitschriftfür Geomorphologie Supplementband, 1-17, 1999.

Owen, R. P.: Saltation of uniform grains in air, J. Fluid. Mech., 20, 225-242, 1964.

Rasmussen, K. R, Valance, A., and Merrison, J.: Laboratory studies of aeolian sediment transport processes on planetary surfaces, Geomorphology, 244, 74-94, 2015.

Rice, M. A., Willetts, B. B., and McEwan, I. K.: Observations of collisions of saltating grains with a granular bed from high-speed cine-film, Sedimentology, 43, 21-31, 1996a.

Rice, M. A., Willetts, B. B., and McEwan, I. K.: Wind erosion of crusted soil sediments, Earth Surf. Proc. Land., 21, 279-293, $1996 b$. 
Shao, Y.: A model for mineral dust emission, J. Geophys. Res., 106, 20239-20254, 2001.

Shao, Y.: Simplification of a dust emission scheme and comparison with data, J. Geophys. Res., 109, D10202, doi:10.1029/2003JD004372, 2004.

Shao, Y.: Physics and Modelling of Wind Erosion, Springer, Heidelberg, 2008.

Shao, Y. and Lu, H.: A simple expression for wind erosion threshold friction velocity, J. Geophys. Res., 105, 22437-22443, 2000.

Shao, Y. and Raupach, M. R.: The overshoot and equilibration of saltation, J. Geophys. Res., 97, 20559-20564, 1992.

Shao, Y., Raupach, M. R., and Findlater, P. A.: The effect of saltation bombardment on the entrainment of dust by wind, J. Geophys. Res., 98, 12719-12726, 1993.

Shao, Y., Raupach, M. R., and Leys, J. F.: A model for predicting Aeolian sand drift and dust entrainment on scales from paddock to region, Aust. J. Soil. Res., 34, 309-342, 1996.

Shao, Y., Ishizuka, M., Mikami, M., and Leys, J. F.: Parameterization of size-resolved dust emission and validation with measurements, J. Geophys. Res., 116, D08203, doi:10.1029/2010JD014527, 2011.
Sow, M., Alfaro, S. C., Rajot, J. L., and Marticorena, B.: Size resolved dust emission fluxes measured in Niger during 3 dust storms of the AMMA experiment, Atmos. Chem. Phys., 9, 38813891, doi:10.5194/acp-9-3881-2009, 2009.

Sweeney, M. R. and Mason, J. A.: Mechanisms of dust emission from Pleistocene loess deposits, Nebraska, USA, J. Geophys. Res.-Ea. Surf., 118, 1460-1471, 2013.

Újvári, G., Kok, J. F., György, V., and Kovács, J.: The physics of wind-blown loess: Implications for grain size proxy interpretations in Quaternary paleoclimate studies, Earth Sci. Rev., 154, 247-278, doi:10.1016/j.earscirev.2016.01.006, 2016.

Zhang, J.: A Study on Dust Dry Deposition: Wind-tunnel Experiment and Improved Parameterization, PhD thesis, Cologne University, Cologne, Germany, 2013.

Zhang, J., Shao, Y., and Huang, N.: Measurements of dust deposition velocity in a wind-tunnel experiment, Atmos. Chem. Phys., 14, 8869-8882, doi:10.5194/acp-14-8869-2014, 2014. 